\title{
Does a fluorinated Lewis acid catalyst change the molecular mechanism of the decomposition process of nitroethyl carboxylates?
}

\author{
Agnieszka Kącka ${ }^{1} \cdot$ Luis R. Domingo ${ }^{2} \cdot$ Radomir Jasiński $^{1}$
}

Received: 8 May 2017/ Accepted: 10 August 2017/Published online: 31 August 2017

(C) The Author(s) 2017. This article is an open access publication

\begin{abstract}
The molecular mechanism of the decomposition reaction of nitroethyl benzoates catalyzed by Lewis acids based on boron element- $\mathrm{BH}_{3}$ and $\mathrm{BF}_{3}-$ was studied using density functional theory methods. These reactions take place much faster than the uncatalyzed process. However, the presence of fluorinated Lewis acids has a unique influence on the molecular mechanism. In the case of $\mathrm{BF}_{3}, \mathrm{a}$ change from a one-step mechanism to a two-step one involving a zwitterionic intermediate is observed.
\end{abstract}

Keywords Thermal elimination · DFT study $\cdot$ Nitroalkene $\cdot$ Fluorine effect

\section{Introduction}

Conjugated nitroalkenes (CNAs) are valuable precursors for a wide variety of building blocks and intermediates in organic synthesis [1-3]. These compounds are found to be important because of their biological activities, such as insecticidal [4, 5], fungicidal [5-8], bactericidal [9, 10], and antitumor effects [11], including pharmacologically valuable substances [6-9]. They have proved to be valuable precursors for a wide variety of target molecules. The versatility of the nitro group enables its transformation into many compounds with diverse functionalities [12-14]. Furthermore, CNAs are strong electrophilic ethylenes participating in polar

Agnieszka Kącka

akacka@chemia.pk.edu.pl

1 Institute of Organic Chemistry and Technology, Cracow University of Technology,

Warszawska 24, 31-155 Cracow, Poland

2 Departamento de Química Orgánica, Universidad de Valencia, Dr. Moliner 50, Burjassot, 46100 Valencia, Spain 
Diels-Alder reactions, and alternatively these electrophilic species readily undergo addition reactions with various nucleophiles, thus providing an array of valuable products [11].

Thermal decomposition of alkyl esters to produce alkenes and carboxylic acids is a well-established process that has been studied for over a century $[15,16]$. Although some of the decomposition reactions for preparation of nitroalkenes are productive, many of them require strict reaction conditions, are expensive, and lead to low yield of nitroalkenes. Examples include elimination of carboxylic acid from nitroalkyl benzoates carried out at temperature of $180-190{ }^{\circ} \mathrm{C}$ [17], and decomposition of nitroalkyl phthalates, which proceeds at $170-185^{\circ} \mathrm{C}$ [18]. Additionally, highly reactive nitroalkenes rapidly polymerize under these conditions [19]. Research in this field to identify benign conditions for obtaining conjugated nitroalkenes is therefore essential.

This work is a continuation of our extensive study on the synthesis and fundamental properties of CNAs. Previously [20, 21], we analyzed mechanistic aspects of the decomposition of nitroalkyl carboxylates under thermal conditions. We demonstrated that thermal decomposition of nitroethyl carboxylates should not be recognized as a pericyclic but rather as a two-stage one-step process [22]. We also performed quantum-chemical calculations on the decomposition of nitroalkyl carboxylates catalyzed by triethylsulfonium (TES), triethylphosphonium (TEP) [23], and 1,3-dimethylimidazolium (DMIM) [24] cations. We proved that, in presence of TES, TEP, and DMIM cations, the decomposition process of nitroethyl benzoates takes place much faster than in the same process without catalyst.

It is well known that use of Lewis acids can lead to significant changes in the nature of the molecular mechanism in comparison with the uncatalyzed process [25]. The aim of this work is a quantum-chemical study on the molecular mechanism of the decomposition reactions of model nitroethyl benzoates, without or in presence of inorganic Lewis acid (LA) catalysts, viz. borane $\left(\mathrm{BH}_{3}\right)$ and boron trifluoride $\left(\mathrm{BF}_{3}\right)$ (Scheme 1).

These catalysts have also been applied for other types of fundamental reaction, for instance, polar Diels-Alder [26-28] or [3 + 2]-cycloaddition reactions [29]. The decomposition process of nitroethyl carboxylates is carried out in dichloromethane environment, because it is a good solvent for LAs [26, 27, 30, 31].

\section{Results and discussion}

As shown by M06-2X/6-31 + G(d) calculations, the first step of the decomposition reaction of nitroethyl benzoate (1a) is formation of a prereaction complex $\left(\mathbf{1 a}_{\mathbf{a}}\left[\mathbf{B H}_{3}\right]\right)$ between the ester and the $\mathrm{LA}-\mathrm{BH}_{3}$. Electron-deficient molecules, such as $\mathrm{BF}_{3}$ and $\mathrm{BH}_{3}$, contain less than an octet of electrons around one atom, showing a strong tendency to gain an additional pair of electrons by reacting with substances that possess a lone pair of electrons. As a result, a bond is formed. The bond formed between a Lewis acid $\left(\mathrm{BH}_{3}\right)$ and nitroethyl benzoate (1a) is a coordinate covalent bond, because both electrons are provided by only one of the atoms. After it is formed, however, a coordinate covalent bond behaves like any other covalent single 


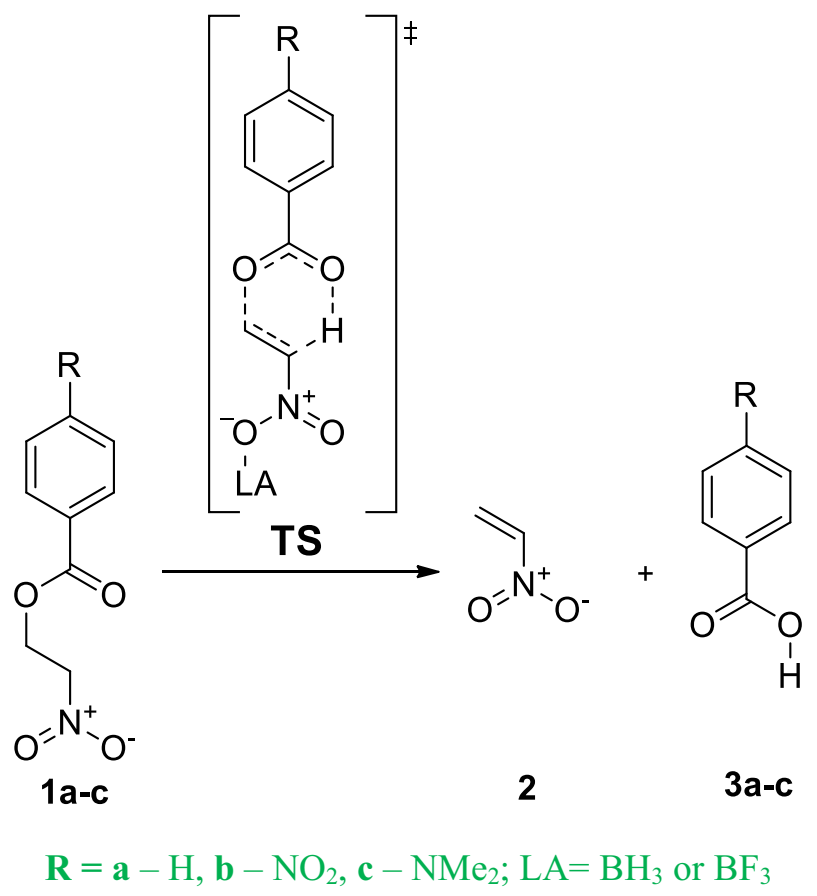

Scheme 1 Mechanism of LA-catalyzed decomposition reaction of nitroethyl benzoates 1a-c

bond. Consequently, the creation of a prereaction complex entails a drop in reaction enthalpy by $15.0 \mathrm{kcal} \mathrm{mol}^{-1}$ (Fig. 1, Table 1). The LA catalyst- $\mathrm{BH}_{3}$-is located near to the oxygen atom of the nitro group. We also analyzed many other orientations of the $\mathrm{LA} \mathrm{BH}_{3}$ catalyst to the ester molecule. For subsequent research, we chose the most stable form.

Further conversion of the reacting system along the reaction coordinate leads to the transition state structure (TS). As these data from M06-2X/6-31 + G(d) calculations show, this is related to an enthalpy increase of over $31.9 \mathrm{kcal} \mathrm{mol}^{-1}$ for the reaction catalyzed by the $\mathrm{LA} \mathrm{BH}_{3}$. This barrier, however, is much smaller than suggested by the DFT calculations for a similar decomposition reaction without LA catalysis (about $39.5 \mathrm{kcal} \mathrm{mol}^{-1}$ ) (Fig. 1, Table 2). Afterwards, the TS is converted to products 2 and 3a (Figs. 1, 2).

In the structure of transition states, a $\mathrm{C}-\mathrm{H}$ single bond between $\mathrm{O} 5$ and $\mathrm{H} 6$ atoms is formed. Two double bonds are formed between the $\mathrm{C} 1-\mathrm{C} 2$ and $\mathrm{O} 3-\mathrm{C} 4$ atoms, the C4-O5 bond is changed to a single bond, and the H6-C1 bond becomes broken (Fig. 3, Table 3).

On the basis of the calculations performed, we also analyzed the influence of the LA $\mathrm{BH}_{3}$ catalyst in the structure of TS. It turned out that the H6-C1 bond in the reaction catalyzed by the $\mathrm{LA} \mathrm{BH}_{3}$ is broken earlier than in the uncatalyzed process. In TS, the rupture of the O5-H6 single bond is in any case very advanced. The global electron density transfer (GEDT) value for the transition state for the 


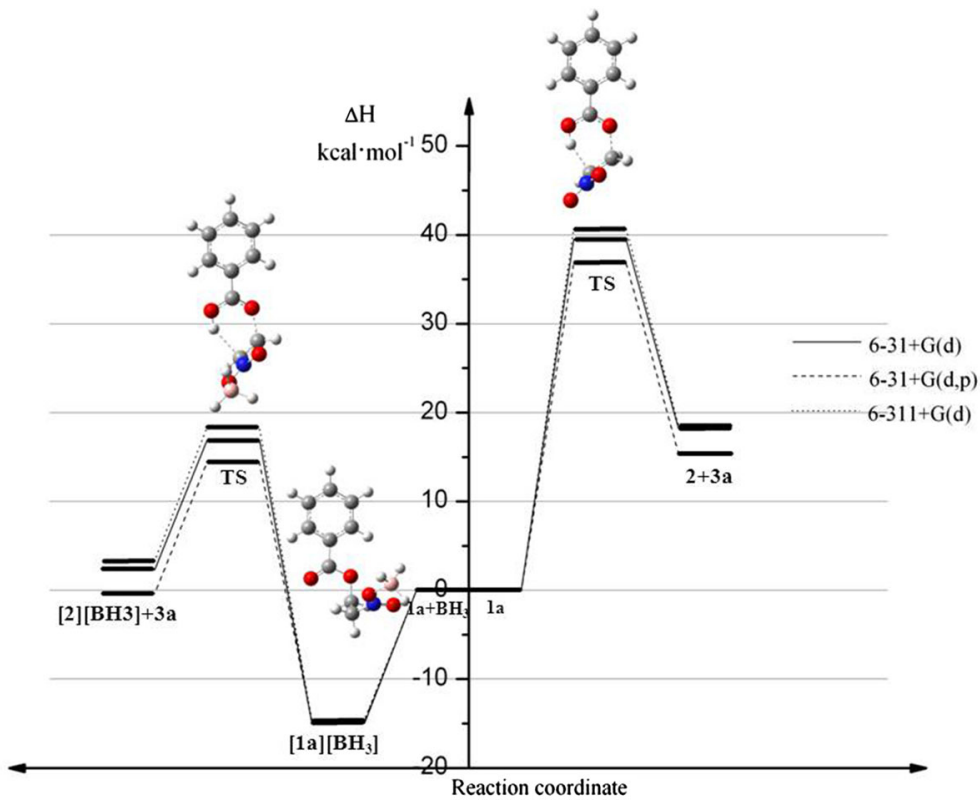

Fig. 1 M06-2X/6-31 + G(d) enthalpy profiles for decomposition of nitroethyl benzoate 1a, catalyzed by $\mathrm{BH}_{3}$ and without catalyst

Table 1 M06-2X/6-

$31+\mathrm{G}(\mathrm{d})$ kinetic and thermodynamic parameters for decomposition of nitroethyl benzoates catalyzed by $\mathrm{BH}_{3}$ according to M06-2X calculations $(T=298 \mathrm{~K} ; \Delta H$, $\Delta G$ in kcal mol ${ }^{-1}, \Delta S$ in cal $\mathrm{mol}^{-1} \mathrm{~K}^{-1}$; $\mathbf{1 a} \mathrm{R}=\mathrm{H}, \mathbf{1 b}$ $\mathrm{R}=\mathrm{NO}_{2}, \mathbf{1 c} \mathrm{R}=\mathrm{NMe}_{2}$ )

\begin{tabular}{|c|c|c|c|c|}
\hline Ester & Transition & $\Delta H$ & $\Delta G$ & $\Delta S$ \\
\hline \multirow[t]{3}{*}{$1 \mathbf{a}$} & $\mathbf{1 a}+\mathrm{BH}_{3} \rightarrow[\mathbf{1 a}]\left[\mathbf{B H}_{3}\right]$ & -15.0 & -4.2 & -36.1 \\
\hline & {$[\mathbf{1 a}]\left[\mathbf{B H}_{3}\right] \rightarrow \mathbf{T S}$} & 31.9 & 32.2 & -1.0 \\
\hline & {$[1 \mathbf{a}]\left[\mathrm{BH}_{3}\right] \rightarrow[2]\left[\mathrm{BH}_{3}\right]+3 \mathbf{a}$} & 17.3 & 5.2 & 40.6 \\
\hline \multirow[t]{3}{*}{$1 \mathbf{b}$} & $\mathbf{1 b}+\mathrm{BH}_{3} \rightarrow[\mathbf{1 b}]\left[\mathbf{B H}_{\mathbf{3}}\right]$ & -14.9 & -3.1 & -39.5 \\
\hline & {$[\mathbf{1 b}]\left[\mathrm{BH}_{3}\right] \rightarrow \mathrm{TS}$} & 34.1 & 33.8 & 0.4 \\
\hline & {$[1 \mathrm{~b}]\left[\mathrm{BH}_{3}\right] \rightarrow[2]\left[\mathrm{BH}_{3}\right]+3 \mathrm{~b}$} & 17.3 & 4.3 & 43.6 \\
\hline \multirow[t]{3}{*}{ 1c } & $\mathbf{1 c}+\mathrm{BH}_{3} \rightarrow[\mathbf{1 c}]\left[\mathrm{BH}_{3}\right]$ & -15.3 & -4.2 & -37.5 \\
\hline & {$[1 \mathrm{c}]\left[\mathrm{BH}_{3}\right] \rightarrow \mathrm{TS}$} & 29.2 & 30.3 & -3.9 \\
\hline & {$[1 \mathrm{c}]\left[\mathrm{BH}_{3}\right] \rightarrow[2]\left[\mathrm{BH}_{3}\right]+3 \mathrm{c}$} & 17.8 & 5.6 & 40.7 \\
\hline
\end{tabular}

decomposition reaction catalyzed by the Lewis acid $\mathrm{BH}_{3}$ is $0.40[\mathrm{e}]$. This value is comparable to the GEDT value for the transition state of similar noncatalytic processes. TS structures have a polar nature, as proved by the values of GEDT indices and their dipole moments (Table 3).

The nature of the substituent on the benzene ring also has an impact on the TS, in the case of catalytic reactions and those carried out without presence of catalyst. In the case of the reactions $[\mathbf{1 b}]\left[\mathbf{B H}_{\mathbf{3}}\right] \rightarrow[2]\left[\mathbf{B H}_{\mathbf{3}}\right]+\mathbf{3 b}$, the H6-C1 and C2-O3 bonds are broken more slowly than the same bonds in the reaction $[\mathbf{1 a}]\left[\mathbf{B H}_{3}\right] \rightarrow[2]\left[\mathbf{B H}_{3}\right]+\mathbf{3 a}$. In turn, the $\mathrm{H} 6-\mathrm{C} 1$ and $\mathrm{C} 2-\mathrm{O} 3$ bonds in the case 
Table 2 M06-2X/6-31 + G(d) kinetic and thermodynamic parameters for decomposition of nitroethyl benzoates according to M06-2X calculations $\left(T=298 \mathrm{~K} ; \Delta H, \Delta G\right.$ in kcal mol ${ }^{-1}, \Delta S$ in cal mol ${ }^{-1} \mathrm{~K}^{-1}$; 1a $\mathrm{R}=\mathrm{H}, \mathbf{1 b} \mathrm{R}=\mathrm{NO}_{2}, \mathbf{1 c} \mathrm{R}=\mathrm{NMe}_{2}$ )

\begin{tabular}{lllrr}
\hline Ester & Transition & $\Delta H$ & \multicolumn{1}{c}{$\Delta G$} & \multicolumn{1}{c}{$\Delta S$} \\
\hline $\mathbf{1 a}$ & $\mathbf{1 a} \rightarrow \mathbf{T S}$ & 39.5 & 40.2 & -2.2 \\
& $\mathbf{1 a} \rightarrow \mathbf{2}+\mathbf{3 a}$ & 18.2 & 6.4 & 39.8 \\
$\mathbf{1 b}$ & $\mathbf{1 b} \rightarrow \mathbf{T S}$ & 41.4 & 42.6 & -4.2 \\
& $\mathbf{1 b} \rightarrow \mathbf{2}+\mathbf{3 b}$ & 18.3 & 6.6 & 39.3 \\
$\mathbf{1 c}$ & $\mathbf{1 c} \rightarrow \mathbf{T S}$ & 37.4 & 38.3 & -2.9 \\
& $\mathbf{1 c} \rightarrow \mathbf{2}+\mathbf{3 c}$ & 18.4 & 6.6 & 39.5 \\
\hline
\end{tabular}

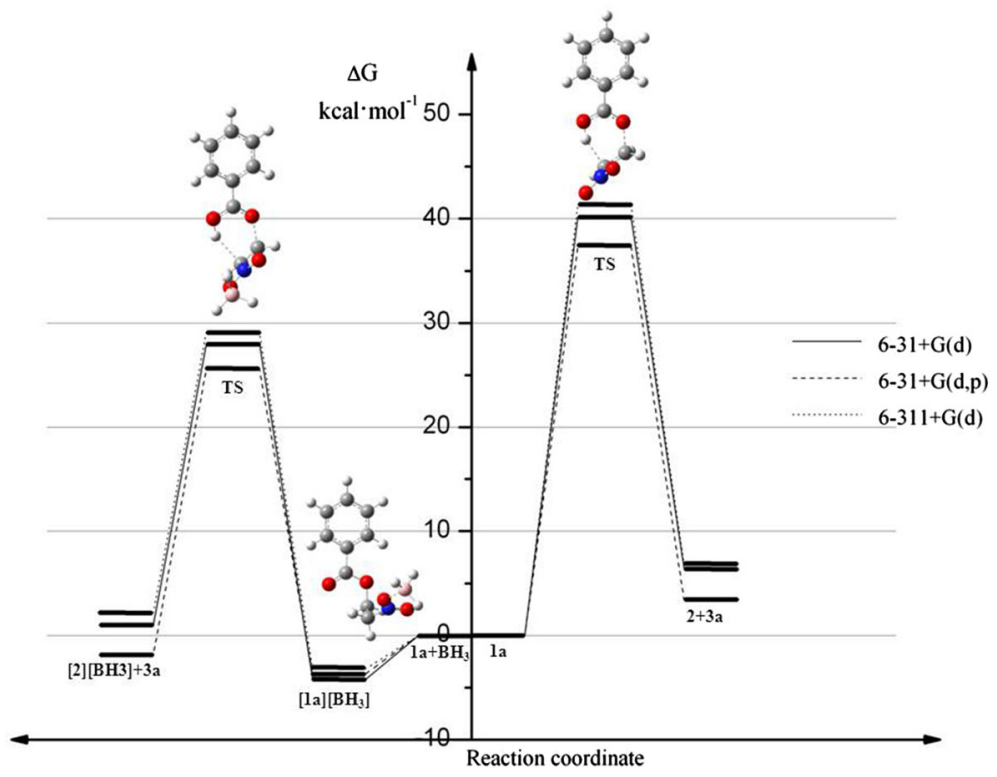

Fig. 2 M06-2X/6-31 + G(d) Gibbs free energy profiles for decomposition of nitroethyl benzoate 1a, catalyzed by $\mathrm{BH}_{3}$ and without catalyst

of the reaction $[\mathbf{1 c}]\left[\mathbf{B H}_{\mathbf{3}}\right] \rightarrow[2]\left[\mathbf{B H}_{3}\right]+\mathbf{3 c}$ are broken faster than in the case of the reaction $[\mathbf{1 a}]\left[\mathbf{B H}_{\mathbf{3}}\right] \rightarrow[2]\left[\mathbf{B H}_{\mathbf{3}}\right]+\mathbf{3 a}$ (Table 3$)$.

It should also be mentioned that DFT study using the same M06-2X functional but with larger $6-31+\mathrm{G}(\mathrm{d}, \mathrm{p})$ and $6-311+\mathrm{G}(\mathrm{d})$ basis sets gives a similar representation of these reactions. These calculations show that the mechanism of the decomposition reaction of nitroalkyl carboxylates catalyzed by the $\mathrm{LA} \mathrm{BH}_{3}$ and without catalyst are also suggestive of a one-step mechanism. In the case of calculations based on M06-2X/6-31 + G(d,p) theory level, we observed a decrease in the activation enthalpy (Figs. 1, 2). 
Fig. 3 M06-2X/6-

$31+\mathrm{G}(\mathrm{d})$ geometry of TSs of decomposition of nitroethyl benzoate 1a, catalyzed by $\mathrm{BH}_{3}$ and without catalyst
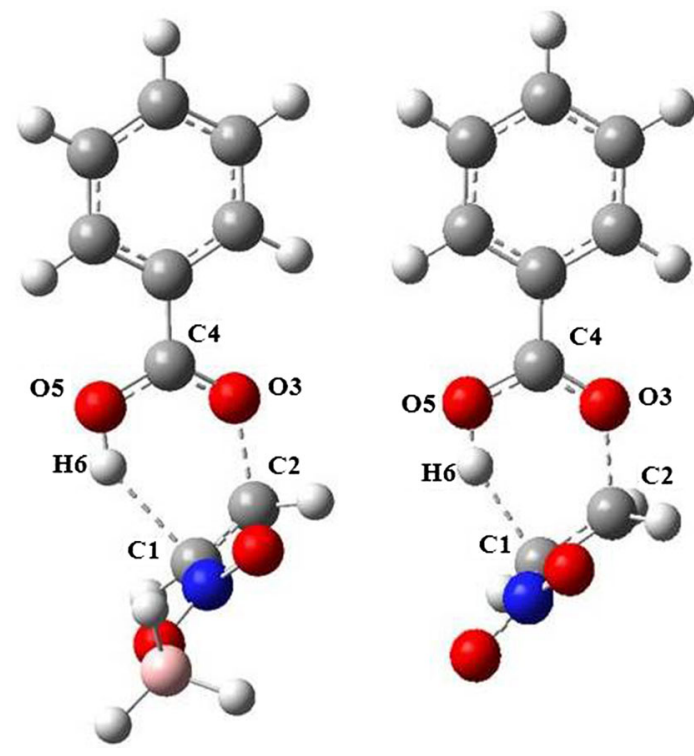

The situation is quite different in the case of the decomposition reaction of nitroethyl carboxylate catalyzed by the $\mathrm{LA} \mathrm{BF}_{3}$. The results of M06-2X/6$31+\mathrm{G}(\mathrm{d})$ calculations showed that the first step of the decomposition of nitroethyl benzoate (1a) is also formation of a prereaction complex $(\mathbf{1} \mathbf{a}[\mathbf{B F} \mathbf{3}])$. Consequently, the creation of a prereaction complex entails a drop of reaction enthalpy by $10.5 \mathrm{kcal} \mathrm{mol}^{-1}$ (Fig. 4). Nonetheless, the Gibbs free energy for this transition is equal to $1.0 \mathrm{kcal} \mathrm{mol}^{-1}$ (Fig. 4). This is a consequence of large negative entropy changes, linked to an increase in the ordering of the reaction system. The $\mathrm{BF}_{3}$ molecule is also located near to the oxygen atom of the nitro group, but is bonded to an oxygen atom other than the $\mathrm{BH}_{3}$ molecule. We analyzed many other orientations of the $\mathrm{BF}_{3}$ catalyst to the ester molecule, but for further research we chose the most stable form.

Thereafter, the prereaction complex is recast to $\mathbf{T S}_{\mathbf{1}}$. This transition requires an activation enthalpy which is more than $22 \mathrm{kcal} \mathrm{mol}^{-1}$ (Fig. 4, Table 4). However, it is significantly less than in the case of the decomposition process of 1a without presence of the $\mathrm{LA} \mathrm{BF}_{3}$ (about $39.5 \mathrm{kcal} \mathrm{mol}^{-1}$ ).

In $\mathbf{T S}_{\mathbf{1}}$, one single bond breaks (Fig. 5, Table 5). It is the bond between the $\mathrm{C} 1$ and H6 atoms. Subsequently, a new single bond between atoms H6 and O5 is formed. It should be mentioned that, in contrast to the $\mathrm{LA}-\mathrm{BH}_{3}$-catalyzed decomposition reaction of $\mathbf{1 a}$ and to the uncatalyzed process, the second single bond C2-O3 is not broken at this reaction stage. $\mathbf{T S}_{\mathbf{1}}$ has an evidently polar, "zwitterionic-like" nature. This is substantiated by the value of the global electron density transfer (GEDT), which is equal to $0.43[\mathrm{e}]$.

Further advance of the reaction leads to intermediate $\mathbf{I}$. I has a polar, zwitterionic nature, as confirmed by the GEDT value $(0.46[\mathrm{e}])$ and dipole moment (15.67[D]). Decomposition of this intermediate proceeds via $\mathbf{T S}_{\mathbf{2}}$. This step requires energy of 


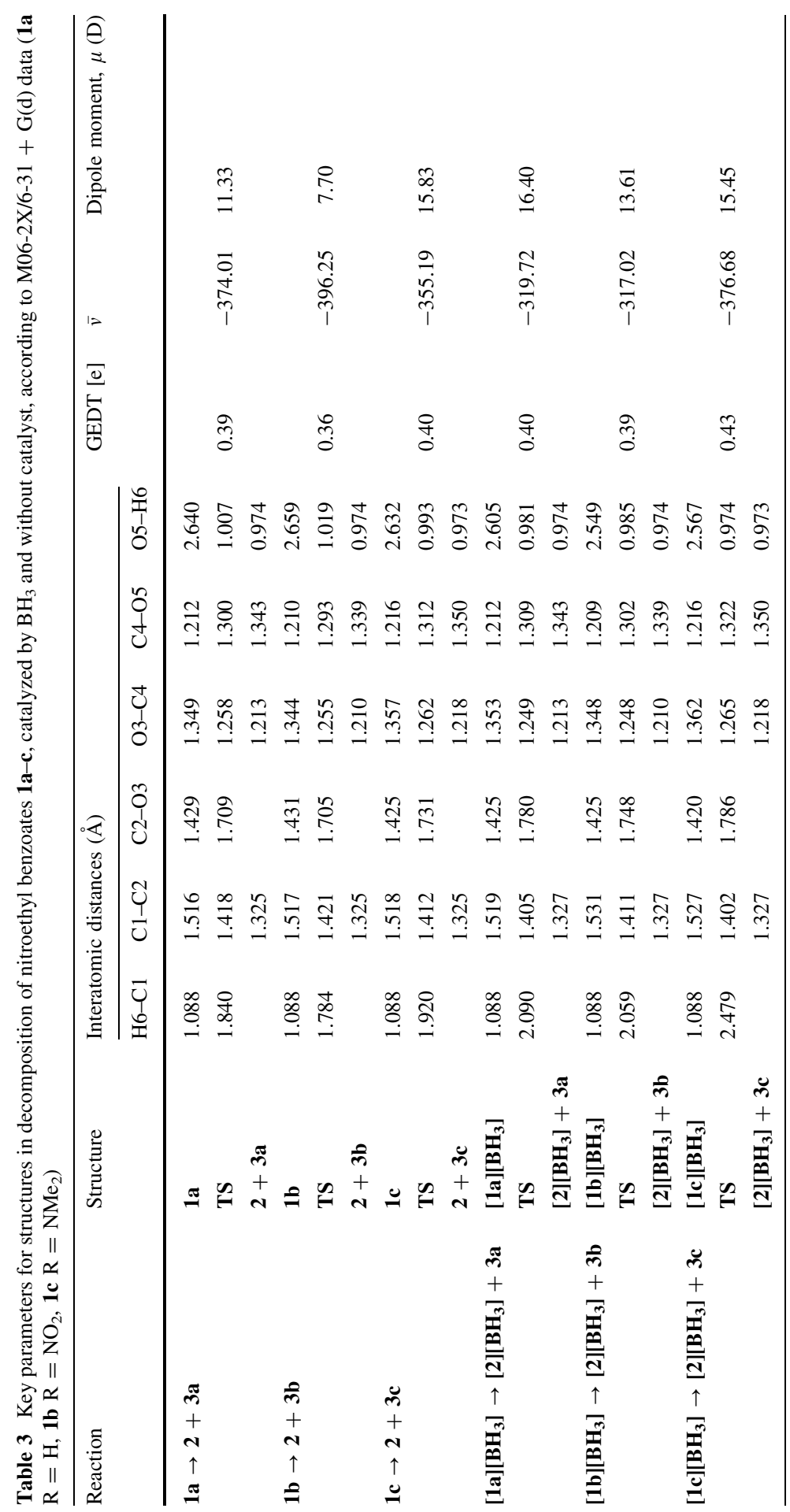




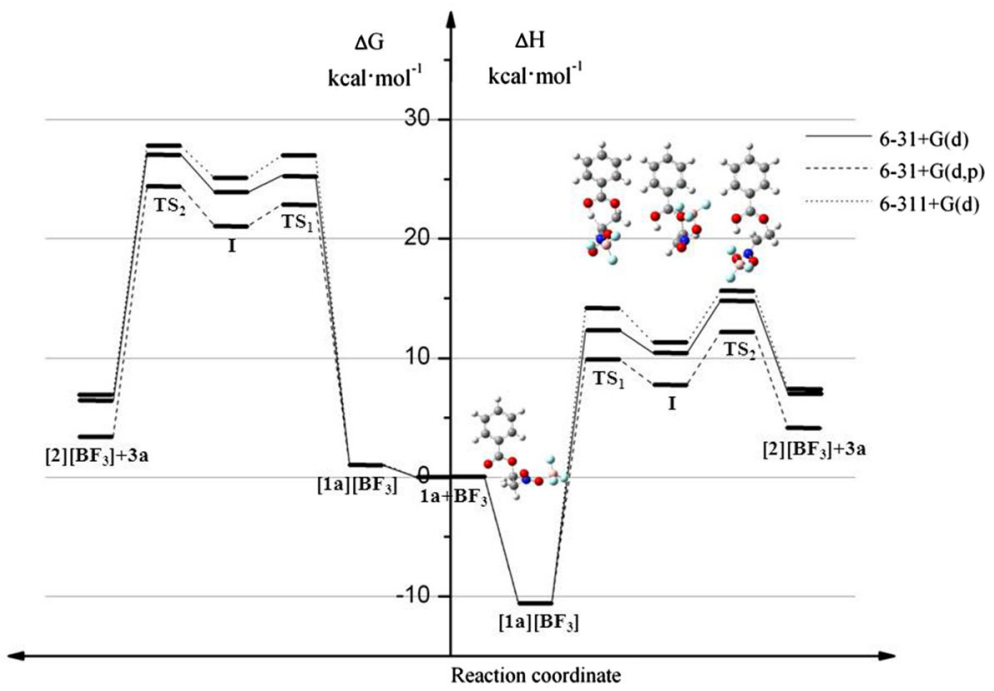

Fig. 4 M06-2X/6-31 + G(d) enthalpy and Gibbs free energy profiles for decomposition of nitroethyl benzoate $1 \mathrm{a}$ catalyzed by $\mathrm{BF}_{3}$

Table 4 M06-2X/6-

$31+\mathrm{G}(\mathrm{d})$ kinetic and thermodynamic parameters for $\mathrm{LA} \mathrm{BF}_{3}$-catalyzed decomposition of nitroethyl benzoates according to M06-2X calculations $(T=298 \mathrm{~K} ; \Delta H$, $\Delta G$ in kcal mol $\mathrm{m}^{-1}, \Delta S$ in cal $\mathrm{mol}^{-1} \mathrm{~K}^{-1}$; $\mathbf{1 a} \mathrm{R}=\mathrm{H}, \mathbf{1 b}$ $\mathrm{R}=\mathrm{NO}_{2}, \mathbf{1 c} \mathrm{R}=\mathrm{NMe}_{2}$ )

\begin{tabular}{|c|c|c|c|c|}
\hline Ester & Transition & $\Delta H$ & $\Delta G$ & $\Delta S$ \\
\hline \multirow[t]{5}{*}{$1 \mathbf{a}$} & $\mathbf{1 a}+\mathrm{BF}_{3} \rightarrow[\mathbf{1 a}]\left[\mathbf{B F}_{\mathbf{3}}\right]$ & -10.5 & 1.0 & -38.6 \\
\hline & {$[\mathbf{1 a}]\left[\mathbf{B F}_{3}\right] \rightarrow \mathbf{T S}_{1}$} & 22.8 & 24.3 & -5.1 \\
\hline & {$[\mathbf{1 a}]\left[\mathbf{B F}_{3}\right] \rightarrow \mathbf{I}$} & 20.9 & 22.9 & -6.7 \\
\hline & {$[\mathbf{1 a}]\left[\mathbf{B F}_{3}\right] \rightarrow \mathbf{T S}_{\mathbf{2}}$} & 25.3 & 26.1 & -2.5 \\
\hline & {$[1 \mathbf{a}]\left[\mathrm{BF}_{3}\right] \rightarrow[2]\left[\mathrm{BF}_{3}\right]+\mathbf{3 a}$} & 17.5 & 5.4 & 40.7 \\
\hline \multirow[t]{5}{*}{$1 \mathbf{b}$} & $\mathbf{1 b}+\mathrm{BF}_{3} \rightarrow[\mathbf{1 b}]\left[\mathbf{B F}_{\mathbf{3}}\right]$ & -10.1 & 1.8 & -39.9 \\
\hline & {$[1 \mathbf{b}]\left[\mathbf{B F}_{3}\right] \rightarrow \mathbf{T S}_{1}$} & 24.9 & 26.0 & -3.5 \\
\hline & {$[\mathbf{1 b}]\left[\mathbf{B F}_{3}\right] \rightarrow \mathbf{I}$} & 23.5 & 24.0 & -1.8 \\
\hline & {$[\mathbf{1 b}]\left[\mathbf{B F}_{3}\right] \rightarrow \mathbf{T S}_{\mathbf{2}}$} & 26.8 & 27.6 & -3.0 \\
\hline & {$[1 \mathrm{~b}]\left[\mathrm{BF}_{3}\right] \rightarrow[2]\left[\mathrm{BF}_{3}\right]+3 \mathrm{~b}$} & 17.2 & 4.8 & 41.7 \\
\hline \multirow[t]{5}{*}{$1 c$} & $\mathbf{1 c}+\mathrm{BF}_{3} \rightarrow[\mathbf{1 c}]\left[\mathbf{B F}_{3}\right]$ & -11.1 & -0.3 & -35.6 \\
\hline & {$[1 \mathrm{c}]\left[\mathrm{BF}_{3}\right] \rightarrow \mathrm{TS}_{1}$} & 20.1 & 22.4 & -7.8 \\
\hline & {$[1 \mathbf{c}]\left[\mathrm{BF}_{3}\right] \rightarrow \mathbf{I}$} & 16.2 & 19.0 & -9.4 \\
\hline & {$[\mathbf{1 c}]\left[\mathbf{B F}_{3}\right] \rightarrow \mathbf{T S}_{2}$} & 23.1 & 25.6 & -8.2 \\
\hline & {$[1 \mathrm{c}]\left[\mathrm{BF}_{3}\right] \rightarrow[2]\left[\mathrm{BF}_{3}\right]+3 \mathrm{c}$} & 18.1 & 7.2 & 36.5 \\
\hline
\end{tabular}

$25.3 \mathrm{kcal} \mathrm{mol}^{-1}$ (Fig. 4, Table 4). In the structure of $\mathbf{T S}_{\mathbf{2}}$, the C2-O3 single bond breaks (Fig. 5, Table 5).

We also performed quantum-chemical study on the decomposition of the other nitroethyl benzoates $\mathbf{1 b}$ and $\mathbf{1 c}$. In the reaction $[\mathbf{1 b}]\left[\mathbf{B F}_{\mathbf{3}}\right] \rightarrow[\mathbf{2}]\left[\mathbf{B F}_{\mathbf{3}}\right]+\mathbf{3 b}$, it was found that the H6-C1 and C2-O3 single bonds are broken more slowly $(2.798 \AA$ and $1.845 \AA$ ) than in the reaction $[\mathbf{1} \mathbf{a}]\left[\mathbf{B F}_{\mathbf{3}}\right] \rightarrow[\mathbf{2}]\left[\mathbf{B F}_{\mathbf{3}}\right]+\mathbf{3 a}$. In turn, the H6-C1 


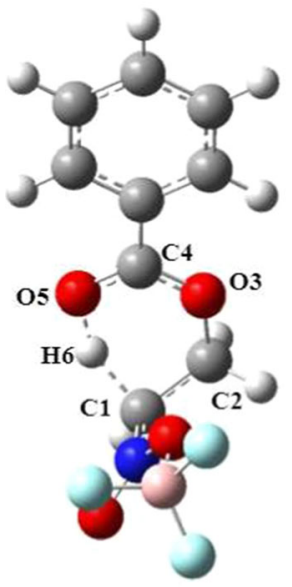

$\mathrm{TS}_{1}$

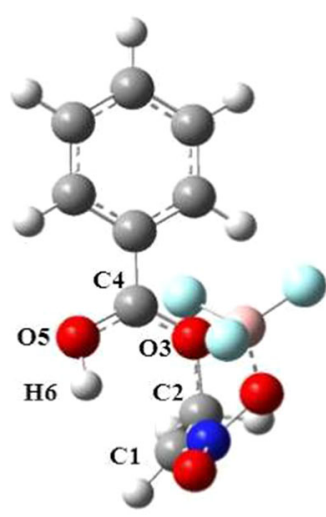

I

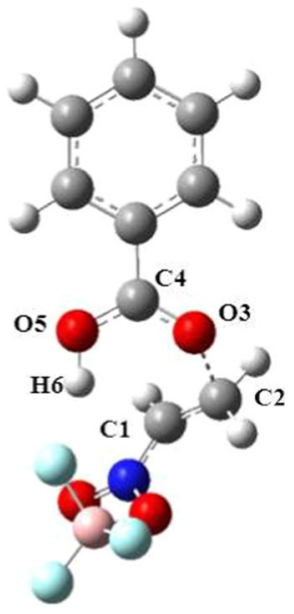

$\mathrm{TS}_{2}$

Fig. 5 M06-2X/6-31 + G(d) geometries of the TSs and intermediate associated with LA- BF 3 -catalyzed decomposition of nitroethyl benzoate $1 \mathbf{a}$

and C2-O3 single bonds are broken faster $(2.952 \AA$ and $1.938 \AA$ ) in the reaction $[\mathbf{1 c}]\left[\mathbf{B F}_{3}\right] \rightarrow[\mathbf{2}]\left[\mathbf{B F}_{3}\right]+\mathbf{3 c}$ than in the case of the reaction $[1 \mathrm{a}]\left[\mathrm{BF}_{3}\right] \rightarrow[2]\left[\mathrm{BF}_{3}\right]+3 \mathrm{a}$.

The decompositions of the nitroethyl benzoates $1 \mathbf{a}-\mathbf{c}$ proceed according to a similar mechanistic scheme at the higher theory levels of M06-2X/6-31 + G(d,p) and M06-2X/6-311 + G(d). Calculations at M06-2X/6-31 + G(d,p) level gave slightly lower activation enthalpy (Fig. 4).

On the grounds of the quantum-chemical calculations, we propose the mechanisms of the decomposition reactions of nitroethyl benzoates $1 \mathbf{a}-\mathbf{c}$ catalyzed by the $\mathrm{LAs} \mathrm{BH}_{3}$ and $\mathrm{BF}_{3}$ shown in Scheme 2. It turned out that the $\mathrm{LA} \mathrm{BH}_{3}$ catalyzed decomposition reactions of nitroethyl carboxylates proceed via a polar one-step mechanism. In turn, the decomposition of nitroethyl carboxylates catalyzed by the fluorinated $\mathrm{LA}^{\mathrm{BF}} 3$ proceeds via a two-step mechanism involving a zwitterionic intermediate.

\section{Computational details}

All calculations reported in this paper were performed on the "Prometheus" computer cluster in the CYFRONET regional computer center in Cracow. The mechanism of decomposition of nitroalkyl benzoates catalyzed by LAs was examined as implemented in the GAUSSIAN 09 package [32]. The geometric parameters for all the reactants, TSs, and products of the reactions studied were fully optimized using the density functional theory (DFT) method. The calculations were performed at M06-2X level with the 6-31 + G(d) basis set. The B3LYP functional was replaced by M06-2X because of its increased accuracy. Additionally, 


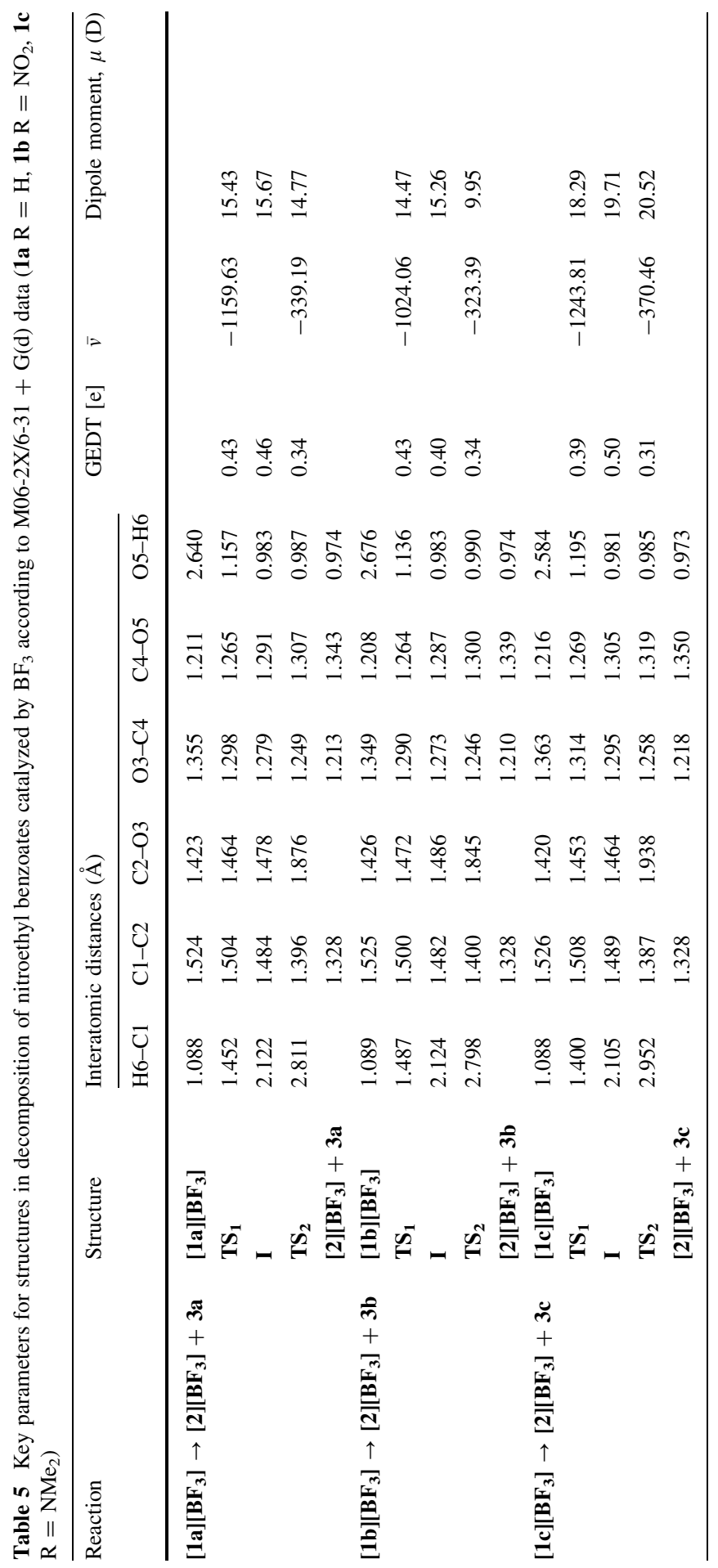




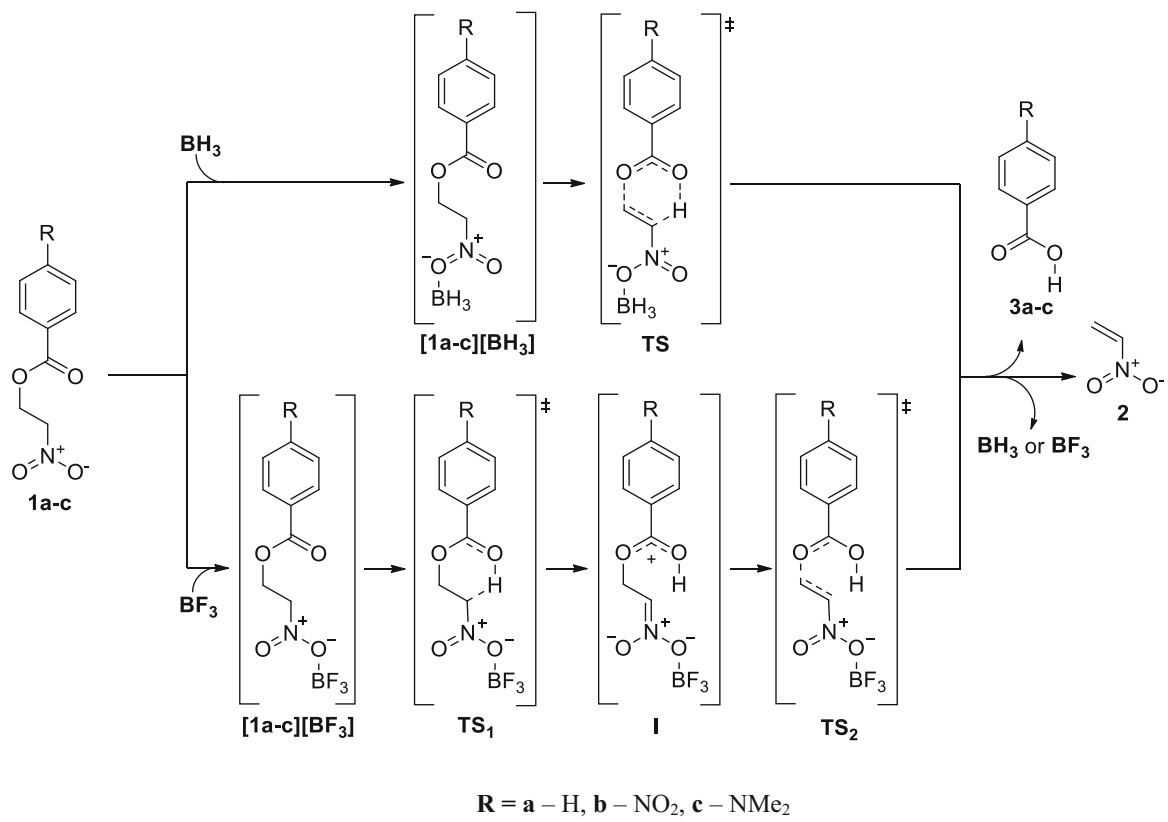

Scheme 2 Mechanisms of decomposition reaction of nitroethyl benzoates $\mathbf{1 a}-\mathbf{c}$ catalyzed by $\mathrm{LAs} \mathrm{BH}_{3}$ and $\mathrm{BF}_{3}$

calculations using the more advanced 6-31 + G(d,p) and 6-311 + G(d) basis sets were carried out.

Published reports show that a similar approach was used successfully to explore a reaction involving several different nitro and other compounds [33-35]. M06-2X is a hybrid meta exchange-correlation functional developed recently [36], parameterized to include short-range dispersion energy. Geometry optimization calculations were carried out to obtain the global minima for the reactants and products, and to locate the saddle point for the TS. Stationary points were characterized by frequency calculations. All reactants and products had positive Hessian matrices. All TSs had only one negative eigenvalue in their diagonalized Hessian matrices, and their associated eigenvectors were confirmed to correspond to motion along the reaction coordinate under consideration. TSs were located using the (QST2) algorithm. Intrinsic reaction coordinate (IRC) calculations [37] were carried out for all events to verify that the localized TSs connected with the corresponding minimum stationary points associated with reactants, products, and intermediates.

The reaction environment polarity was simulated using a relatively simple selfconsistent reaction field (SCRF) [38-40] based on the polarizable continuum model (PCM) of Tomasi's group [41-43]. Since the solvent used is usually dichloromethane, we used a dielectric constant at $298.0 \mathrm{~K}$ of $\varepsilon=8.93$.

Charge global electron density transfer (GEDT) [44] was calculated according to the formula 


$$
\mathrm{GEDT}=-\Sigma q_{\mathrm{A}}
$$

where $q_{\mathrm{A}}$ is the net charge and the sum is taken over all the atoms of the substructure.

The values of enthalpies, entropies, and free energies in all calculations were calculated using standard statistical thermodynamics at $25^{\circ} \mathrm{C}$ and $1 \mathrm{~atm}$ [45].

\section{Conclusions}

This quantum-chemical DFT study demonstrates that the $\mathrm{LA} \mathrm{BH}_{3}$-catalyzed decomposition reactions of nitroethyl benzoates proceed via a polar one-step mechanism. By contrast, the decomposition reaction of nitroethyl benzoates catalyzed by the fluorinated $\mathrm{LA} \mathrm{BF}_{3}$ proceeds via a two-step mechanism involving formation of a zwitterionic intermediate. These decomposition reactions, catalyzed by the $\mathrm{LAs} \mathrm{BH}_{3}$ and $\mathrm{BF}_{3}$, take place much faster than the same reactions without catalyst.

Acknowledgements Partial support of this research by PL-Grid Infrastructure and financial support from the Polish State Committee (Grant No. C-2/88/2016/DS) are gratefully acknowledged.

Open Access This article is distributed under the terms of the Creative Commons Attribution 4.0 International License (http://creativecommons.org/licenses/by/4.0/), which permits unrestricted use, distribution, and reproduction in any medium, provided you give appropriate credit to the original author(s) and the source, provide a link to the Creative Commons license, and indicate if changes were made.

\section{References}

1. R. Ballini, R. Castagnani, M. Petrini, J. Org. Chem. 4, 2160 (1992)

2. V.V. Perekalin, E.S. Lipina, V.M. Berestovitskaya, D.A. Efremov, Nitroalkenes: Conjugated Nitroalkenes (Wiley, New York, 1994)

3. S.H. Lee, Y.J. Park, ChM Yoon, Org. Biomol. Chem. 1, 1099 (2003)

4. P.W. Brian, M. Jamieson, J.C. McGowan, Nature 162, 780 (1948)

5. F.C. Bocobo, A.C. Curtis, W.D. Block, E.R. Harrell, E.E. Evans, R.F. Haines, Antibiot. Chemother. 6, 385 (1956)

6. P.W. Brian, J.F. Grove, J.C. McGowan, Nature 158, 876 (1946)

7. J.C. McGowan, P.W. Brian, H.G. Hemming, Ann. Appl. Biol. 35, 25 (1948)

8. Y. Hoashi, T. Yabuta, Y. Takemoto, Tetrahedron Lett. 45, 9185 (2004)

9. O. Schales, H.A. Graefe, J. Am. Chem. Soc. 74, 4486 (1952)

10. S. Kaap, I. Quentin, D. Tamiru, M. Shaheen, K. Eger, H.J. Steinfelder, Biochem. Pharmacol. 65, 603 (2003)

11. K. Zee-Cheng, C. Cheng, J. Med. Chem. 12, 157 (1969)

12. R. Ballini, G. Bosica, Synthesis 7, 723 (1994)

13. A.G.M. Barrent, Chem. Soc. Rev. 20, 95-127 (1991)

14. B.P. Bandgar, L.S. Uppalla, Synth. Commun. 30, 2071 (2000)

15. V.V. Perekalin, E.S. Lipina, V.M. Berestovitskaya, D.A. Efremov, Nitroalkenes: Conjugated Nitroalkenes (Wiley, New York, 1994)

16. R. Alexander, P.G. Kralert, R.I. Kagi, Org. Geochem. 19, 133 (1992)

17. L. Leseticky, V. Fidler, M. Prochazka, Collect. Czechoslov. Chem. Commun. 38, 459 (1973) 
18. G.D. Buckley, C.W. Scaife, J. Chem. Soc. 280, 1471 (1947)

19. B.A.T. Blomquist, W.J. Tapp, J.R. Johnson, J. Am. Chem. Soc. 67, 1519 (1945)

20. R. Jasiński, A. Kącka, J. Mol. Mod. 21, 59 (2015)

21. A. Kącka, R. Jasiński, Heteroatom Chem. 27, 279-289 (2016)

22. L.R. Domingo, J.A. Saéz, R.J. Zaragozá, M. Arnó, J. Org. Chem. 73, 8791-8799 (2008)

23. A. Kącka, R. Jasiński, Phosphorus Sulfur Silicon Relat. Elem. (2017). doi:10.1080/10426507.2017. 1290626

24. A. Kącka, R. Jasiński, Curr. Chem. Lett. 6, 15 (2017)

25. I.H. Sanches, R. Yanez, R. Enriquez, P. Joseph-Nathan, J. Org. Chem. 46, 2818 (1981)

26. L.R. Domingo, M. Arnó, J. Andrés, J. Org. Chem. 64, 5867 (1999)

27. L.R. Domingo, A. Asensio, J. Org. Chem. 65, 1076 (2000)

28. L.R. Domingo, A. Asensio, P. Arroyo, J. Phys. Org. Chem. 15, 660 (2002)

29. J. Tanakap, Sh Kanemasa, Tetrahedron 57, 899 (2001)

30. L.R. Domingo, M.J. Aurell, R. Jalal, M. Esseffar, Comput. Theor. Chem. 986, 6 (2012)

31. L.R. Domingo, P. Perez, D.E. Ortega, J. Org. Chem. 78, 2462-2471 (2013)

32. M.J. Frisch, G.W. Trucks, H.B. Schlegel, G.E. Scuseria, M.A. Robb, J.R. Cheeseman, J.A. Montgomery, T.J. Vreven, K.N. Kudin, J.C. Burant, J.M. Millam, S.S. Iyengar, J. Tomasi, V. Barone, B. Mennucci, M. Cossi, G. Scalmani, N. Rega, G.A. Petersson, H. Nakatsuji, M. Hada, M. Ehara, K. Toyota, R. Fukuda, J. Hasegawa, M. Ishida, Y. Nakajima, O. Honda, O. Kitao, H. Nakai, M. Klene, X. Li, J.E. Knox, H.P. Hratchian, J.B. Cross, C. Adamo, J. Jaramillo, R. Gomperts, R.E. Stratmann, O. Yazyev, A.J. Austin, R. Cammi, C. Pomelli, J.W. Ochterski, P.Y. Ayala, K. Morokuma, G.A. Voth, P. Salvador, J.J. Dannenberg, V.G Zakrzewski, S. Dapprich, A.D. Daniels, M.C. Strain, M.C. Farkas, D.K. Malick, A.D. Rabuck, K. Raghavachari, J.B. Foresman, J.V. Ortiz, Q. Cui, A.G. Baboul, S. Clifford, J. Cioslowski, B.B. Stefanov, G. Liu, A. Liashenko, P. Piskorz, I. Komaromi, R.L. Martin, D.J. Fox, T. Keith, M.A. Al-Laham, C.Y. Peng, A. Nanayakkara, M. Challacombe, P.M.W. Gill, B. Johnson, W. Chen, M.W. Wong, C. Gonzalez, J.A. Pople, Gaussian 09 rev A.1 Gaussian Inc, Wallingford CT, (2009)

33. L. Rhyman, P. Ramasami, J.A. Joule, J.A. Saez, L.R. Domingo, RSC Adv. 3, 447 (2013)

34. D. Rayenne, A.Y. Ouassila, K. Djameleddine, Can. J. Chem. 93, 1115 (2015)

35. Y. Qiao, X. Chen, D. Wei, J. Chang, Sci. Rep. 6, 38200 (2016)

36. Y. Zhao, N.E. Schultz, D.G. Truhlar, J. Chem. Theory Comput. 2, 364 (2016)

37. K. Fukui, J. Phys. Chem. 74, 4161-4163 (1970)

38. O. Tapia, J. Math. Chem. 10, 139 (1992)

39. J. Tomasi, M. Persico, Chem. Rev. 94, 2027 (1994)

40. B.Y. Simkin, I. Sheikhet, Quantum Chemical and Statistical Theory of Solutions-a Computational Approach (Ellis Horwood, Chichester, 1995)

41. M.T. Cances, V. Mennunci, J. Tomasi, J. Chem. Phys. 107, 3032 (1997)

42. M. Cossi, V. Barone, R. Cammi, J. Tomasi, Chem. Phys. Lett. 255, 327 (1996)

43. V. Barone, M. Cossi, J. Tomasi, Comput. Chem. 19, 404 (1998)

44. L.R. Domingo, RSC Adv. 4, 32415 (2014)

45. S. Berski, J. Andres, B. Silvi, L.R. Domingo, J. Phys. Chem. 107, 6014 (2003) 